\title{
Changes in lower incisor irregularity during treatment with oral sleep apnea appliances
}

\author{
Niclas Norrhem $^{1,2} \cdot$ Hans Nemeczek ${ }^{1} \cdot$ Marie Marklund $^{1}$ (I)
}

Received: 1 November 2016/Revised: 19 December 2016 / Accepted: 29 December 2016 / Published online: 23 January 2017

(C) The Author(s) 2017. This article is published with open access at Springerlink.com

\begin{abstract}
Purpose The purpose of this study is to test the hypothesis that a flexible oral appliance without incisor coverage $\left(\mathrm{OA}_{\mathrm{Flex}}\right)$ increases the irregularity of the front teeth compared with a rigid appliance with incisor coverage $\left(\mathrm{OA}_{\text {Rigid }}\right)$ in patients treated for obstructive sleep apnea (OSA).

Method and patients Nineteen patients (10 men) who had used $\mathrm{OA}_{\text {Rigid }}$ and 22 patients (19 men) who had used $\mathrm{OA}_{\text {Flex }}$ with a median age of 61 years (IQR of 56 to 67 years) who had been treated during a median period of 2.9 years (IQR of 2.7 to 3.1 years) were included in the study. There was no difference in age $(p=0.601)$ or treatment time $(p=0.432)$ between the two appliance groups. The patients had clinical examinations, responded to a questionnaire, and had impressions taken for plaster casts. The irregularity of the front teeth was measured by Little's Index, where the combined linear displacement of all the front teeth is assessed. Changes between baseline and follow-up were compared between the two groups.
\end{abstract}

The study was conducted at the Department of Odontology, Umeå University, Sweden, in collaboration with the County Council of Västerbotten.

Marie Marklund

marie.marklund@umu.se

Niclas Norrhem

niklas.norrhem@skane.se

Hans Nemeczek

Hans.Nemeczek@vll.se

1 Department of Odontology, Umeå University, SE-901 87 Umeå, Sweden

2 Centrum för specialisttandvård, ortodonti, Folktandvården Skåne, SE-222 21 Lund, Sweden
Results The $\mathrm{OA}_{\text {Flex }}$ group increased the irregularity of their lower front teeth by $0.3 \mathrm{~mm}(p=0.018)$, while the $\mathrm{OA}_{\text {Rigid }}$ group had unchanged frontal irregularity $(p=0.717)$. The difference between the groups was significant $(p=0.035)$. There were no changes in the irregularity of the upper front teeth in either group. Patient satisfaction with treatment did not differ between the two appliances.

Conclusions The present results support the hypothesis that a flexible OA without incisor coverage increases the irregularity of the lower front teeth compared with a rigid OA with incisor coverage.

Keywords Oral appliances $\cdot$ Mandibular advancement devices $\cdot$ Side effects $\cdot$ Appliance design

\section{Introduction}

Side effects are common during the early phases of oral appliance therapy for obstructive sleep apnea (OSA) [1-22]. Some of these adverse effects may result in adherence problems. Most side effects, such as salivation problems and tender teeth or jaws, decrease during the first months of treatment [8]. Bite changes, in contrast, are aggravated by increased treatment time and are therefore the most detrimental side effect [17].

The fixation of the appliance on the teeth with the lower jaw positioned in an advanced position will generate posteriorly directed forces on the upper dentition and anteriorly directed forces on the lower dentition [23]. These forces may result in reduced overjet and overbite and create posterior open bite during longer-term treatment. Studies confirm that this will occur in the majority of the patients [24]. Four studies have assessed changes in space for the teeth or irregular tooth positions $[1,3,17,20]$. All these four studies used titratable, 
hard acrylic devices that covered all teeth and did not allow mouth opening. Three of these four studies showed reduced crowding of the lower teeth $[3,17,20]$, while one study found no change [1]. One of the four studies observed reduced crowding of the upper teeth [3], while the remaining three studies found no change. The reduction in crowding in the lower arch and not in the upper arch is probably explained by the different force directions that arise from the appliance on the lower and the upper arch, respectively.

The present study was initiated by an observation by a patient at our clinic who had noticed a marked increase in lower incisor irregularity during only a few months' treatment. There was a marked buccal inclination of a lower incisor, which was verified by comparison with previous plaster casts. At that time, she had been using a fairly new type of oral appliance that is flexible in the lateral dimension and lacks stabilization of the front teeth.

It is generally unknown whether appliance design could influence the degree and type of bite change. Most studies of oral appliances (OAs) have used rigid appliances with full occlusal coverage [1-26]. It is possible that a device that does not cover all the teeth and/or is flexible might cause unexpected bite changes. The aim of this study was therefore to test the hypothesis that a specific brand of OA, which in its original design is both flexible and has no incisor coverage, increased the irregularity of the lower front teeth compared with a rigid OA with frontal coverage.

\section{Materials and methods}

\section{Study participants}

Consecutive patients who had received either a rigid type of OA with frontal coverage, $\mathrm{OA}_{\text {Rigid }}$ (SomnoDent, SomnoMed, MAS Nordic, Stockholm) (Fig. 1), or a flexible one, $\mathrm{OA}_{\text {Flex }}$ without frontal coverage (Narval, ResMed, Lyon, France) (Fig. 2), for the treatment of snoring or obstructive sleep apnea, were considered for inclusion in the study. At the planned 2-year follow-up, patients from each appliance group with as equal treatment periods as possible were selected for a clinical assessment and possible inclusion. The patients had received their appliances from the time we started to use the more flexible type of device in December 2010. The exclusion criteria were inadequate plaster casts (mainly plaster fractures of incisors), adherence for $<50 \%$ of the nights or less than half of the nights, concomitant use of CPAP, alveolar bone loss on the incisors defined as an attachment level that was located more than $3 \mathrm{~mm}$ apical to the cementoenamel junction, or diseases such as dementia that might interfere with the study. The study protocol was approved by the ethics review board at Umeå University, and all the patients gave their written informed consent.
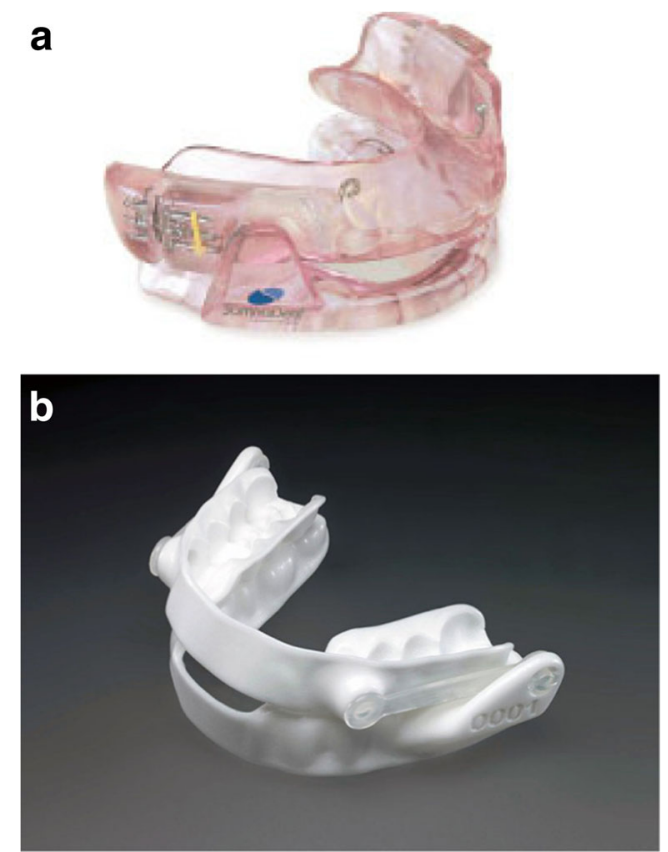

Fig. 1 a The SomnoDent appliance $\left(\mathrm{OA}_{\text {Rigid }}\right)$. b The Narval appliance $\left(\mathrm{OA}_{\text {Flex }}\right)$

\section{Clinical assessment}

At the follow-up, an extended periodontal status assessment, impressions in alginate for plaster casts, and photographs of the appliances were added to the routine examination of the patients.
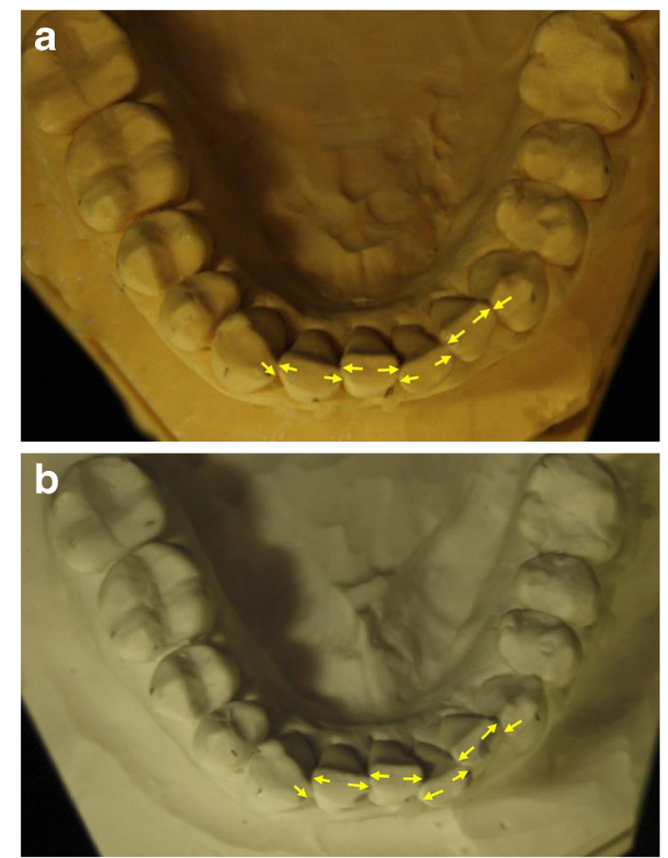

Fig. 2 The pictures show photos of the lower jaw of the subject with the greatest increase in irregularity. a Before. b After. Little's Irregularity Index was calculated from the summarized distances between the contacts points between two adjacent teeth in the frontal areas. The locations of the measurement points are marked in the photos 


\section{Study cast measurements}

All measurements were made blindly with respect to appliance design on the plaster casts at baseline and at follow-up by one investigator $(\mathrm{HN})$.

The irregularity of the front teeth was assessed on the plaster casts using Little's Irregularity Index [27]. The distances between two contact points or other easily identifiable characteristics on the approximal surfaces of two adjacent teeth were measured. Little's Index represents the added distances of all front teeth between the mesial surfaces of the canines in one arch. The measurements were made with a measuring microscope (Leitz UWM-Dig-S, Ernst Leitz GmbH, Wetzlar, Germany). The microscope's accuracy was $0.5 \mu \mathrm{m}$. The space between two adjacent teeth was also measured, and all distances between the mesial surfaces of the canines were summarized. The measurements were repeated after a minimum of 1 week, and the mean value was used in the analyses.

Overjet, overbite, and the intercanine distance were measured with an electronic digital sliding caliper to the nearest $0.01 \mathrm{~mm}$.

The degree of mandibular advancement was measured in the premolar area with the device positioned on the baseline plaster casts compared with the plaster casts located in centric occlusion or relation, if applicable, using a transparent sheet with $1 \mathrm{~mm}$ squares.

\section{Questionnaire}

The questionnaires were coded and contained questions about the estimated use of the appliances, the subjects' satisfaction, and side effects. The patients reported the estimated percentage of nights they had used their appliances. They also assessed how often they had used elastics in order to avoid mouth opening on a scale from $0=$ "never," $1=$ "sometimes" to 2 = "always." Satisfaction with the treatment was reported on a scale from $0=$ "not satisfied," $1=$ "partially satisfied," $2=$ "sufficiently satisfied" to $3=$ "totally satisfied." Side effects were reported on a scale from $0=$ "often," $1=$ "fairly often," 2 = "seldom" to 3 = "never."

\section{Statistical analysis}

Wilcoxon's matched-pairs signed-rank test was performed to test for changes in Little's Irregularity Index in the frontal areas, frontal spacing, overjet, and overbite. The MannWhitney test for independent samples was used to test for differences in baseline characteristics, side effects, and the degree of mandibular advancement between the two appliance groups. Fisher's exact test was used to test whether there were differences in the proportions of men and women between the appliance groups. IBM SPSS Statistics 24.0 was used for data analysis. A $p$ value of less than 0.05 was considered significant.

The sample size was calculated as 15 patients in each group in order to evaluate a change in Little's Irregularity Index of $1 \mathrm{~mm}$ with a power of 0.8 and a significance level of $p<0.05$.

\section{Results}

\section{Study population}

Of 251 consecutively treated patients, 61 patients had received $\mathrm{OA}_{\text {Rigid }}$ and 190 patients had received $\mathrm{OA}_{\mathrm{Flex}}$. Nineteen patients of 24 who had received $\mathrm{OA}_{\text {Rigid }}$ and 22 patients of 25 who had received $\mathrm{OA}_{\text {Flex }}$ were selected for a follow-up control, because of similar treatment periods. Five patients from the $\mathrm{OA}_{\text {Rigid }}$ group were excluded because of alveolar bone loss in the frontal region (1), not used the appliance (1), wanted to wait with the follow-up (2), or used another appliance during the study period (1). Another three patients from the $\mathrm{OA}_{\text {Flex }}$ group were excluded because of alveolar bone loss in the frontal region (1), not used the appliance (1), or wanted to wait with the follow-up (1). The baseline characteristics did not differ between the two appliance groups (Table 1).

\section{Changes in front teeth irregularity}

The irregularity of the lower front teeth increased in the $\mathrm{OA}_{\text {Flex }}$ group by a median value of $0.30 \mathrm{~mm}$ (IQR from 0.00 to 0.69 ) $(p=0.018)$ and was unchanged in the $\mathrm{OA}_{\text {Rigid }}$ group, with a median value of $0.00 \mathrm{~mm}$ (IQR -0.17-0.19) $(p=0.717)$. There was a significant difference between the appliance groups $(p=0.035)$ (Table 2). Two patients in the $\mathrm{OA}_{\text {Flex }}$ group and no patient in the $\mathrm{OA}_{\text {Rigid }}$ group received more than $2 \mathrm{~mm}$ change during the study period. There was no change in the irregularity of the upper front teeth $(p=0.792)$.

\section{Other dental side effects}

The intercanine distances showed minor changes (Table 2). The overjet was unchanged, while the overbite decreased $(p<0.01)$ in both groups, with no difference between them (Table 2).

\section{Subjective effects}

The questionnaires regarding satisfaction with and side effects of the OA treatment revealed no significant differences between the two appliance groups (Table 3). The $\mathrm{OA}_{\text {Flex }}$ group used elastics more frequently than the $\mathrm{OA}_{\mathrm{Rigid}}$ group $(p=0.027)$. 
Table 1 Baseline characteristics

\begin{tabular}{|c|c|c|c|c|c|}
\hline & \multicolumn{2}{|c|}{$\mathrm{OA}_{\text {Flex }}(n=22)$} & \multicolumn{2}{|c|}{$\mathrm{OA}_{\text {Rigid }}(n=19)$} & $p$ value \\
\hline \multirow[t]{2}{*}{ Women/men (\% women) } & \multicolumn{2}{|c|}{ 3/19 (14) } & \multicolumn{2}{|c|}{$9 / 10(47)$} & \multirow[t]{2}{*}{0.144} \\
\hline & Median & IQR & Median & IQR & \\
\hline Age (years) & 61.65 & $55.80-66.78$ & 60.80 & $56.00-66.00$ & 0.601 \\
\hline AHI at start & 15.00 & $10.25-21.00$ & 12.00 & $6.00-21.50$ & 0.437 \\
\hline Overjet at start (mm) & 2.39 & $1.57-4.15$ & 2.85 & $2.35-3.34$ & 0.610 \\
\hline Overbite at start (mm) & 2.71 & $1.26-3.98$ & 2.34 & $1.75-3.48$ & 0.927 \\
\hline Treatment time (years) & 2.80 & $2.61-3.09$ & 3.02 & $2.68-3.05$ & 0.432 \\
\hline Mandibular advancement (mm) & 6.00 & $4.50-7.00$ & 6.00 & $4.00-7.00$ & 0.830 \\
\hline
\end{tabular}

\section{Discussion}

The present study verified our hypothesis that the flexible OA without frontal coverage, $\mathrm{OA}_{\mathrm{Flex}}$, produced an increase in the irregularity of the lower front teeth, while the more rigid appliance with full incisor coverage, $\mathrm{OA}_{\text {Rigid }}$, retained the original appearance of the lower frontal teeth.

A significant increase in the irregularity of the lower incisors of $0.3 \mathrm{~mm}$ was found in the present study. This increase was less than expected from our power calculation of $1 \mathrm{~mm}$ change. Among the four previous studies that investigate space changes in the incisor region, three report less crowding or irregularities $[3,17,20]$. Rose et al., Chen et al., and Pliska et al. found changes of between -1 to $-2 \mathrm{~mm}$ in the lower teeth during the 2 and 11 years' treatment, while Almeida et al. recorded no change after the 4 years' treatment [1]. All these studies used rigid types of oral appliances with full dental coverage $[3,17,20]$. The decrease in crowding or irregularity of the teeth in these previous studies was probably caused by the forwardly directed forces on the lower jaw with an increase in arch length [1,20]. An appliance with occlusal and incisor coverage may cause slight flaring of the lower incisors (increased arch length) due to the anteriorly directed forces.
With an appliance without a rigid incisor coverage, the posterior teeth also drift forward reducing the arch length due to force direction, but without flaring, and the reduced arch length results in incisor irregularity. The present finding therefore contrasts to previous findings and indicates that an adjustment to the design of the investigated type of flexible OA is advisable.

Two possible design details in this specific brand of oral appliance, the $\mathrm{OA}_{\mathrm{Flex}}$, could hypothetically explain the increased irregularity of the lower front teeth after some years' treatment. Firstly, the lack of support for the lower incisors means that these teeth are free to move in an uncontrolled way compared with what is possible in an appliance that fixes and covers all single front teeth. Secondly, the flexibility of the appliance in the lateral dimension may compress the dental arch and cause incisor irregularities compared with what is possible with a rigid type of device. From the present results, it is impossible to know which if any of these mechanisms caused the detected increase in the irregularity of the lower front teeth.

Our study revealed minor changes in the intercanine distance in both arches. This is in contrast to three previous studies that found an increase in mandibular intercanine distance
Table 2 Changes by the flexible $\mathrm{OA}\left(\mathrm{OA}_{\mathrm{Flex}}\right)$ and the rigid $\mathrm{OA}$ $\left(\mathrm{OA}_{\text {Rigid }}\right)$

\begin{tabular}{lllllll}
\hline & \multicolumn{2}{l}{$\mathrm{OA}_{\text {Flex }}(n=22)$} & & \multicolumn{2}{l}{$\mathrm{OA}_{\text {Rigid }}(n=19)$} & Difference \\
\cline { 2 - 3 } & Median & IQR & & Median & IQR & $p$ value \\
\hline Little's Index upper (mm) & 0.00 & $-0.21-0.19$ & & 0.00 & $-0.16-0.09$ & 0.792 \\
Little's Index lower (mm) & $0.30^{\mathrm{a}}$ & $0.00-0.69$ & & 0.00 & $-0.17-0.19$ & 0.035 \\
Spacing upper (mm) & 0.00 & $0.00-0.00$ & & 0.00 & $0.00-0.00$ & 0.484 \\
Spacing lower (mm) & 0.00 & $0.00-0.00$ & & 0.00 & $0.00-0.00$ & 0.335 \\
Overjet (mm) & 0.00 & $-0.32-0.36$ & -0.16 & $-0.27-0.06$ & 0.601 \\
Overbite (mm) & $-0.70^{\mathrm{b}}$ & $-1.22-0.00$ & $-0.36^{\mathrm{c}}$ & -0.73 to -0.15 & 0.266 \\
Intercanine distance upper (mm) & -0.09 & $-0.20-0.30$ & $-0.17^{\mathrm{d}}$ & $-0.45-0.07$ & 0.139 \\
Intercanine distance lower (mm) & -0.06 & $-0.48-0.08$ & -0.03 & $-0.17-0.36$ & 0.120 \\
\hline
\end{tabular}

${ }^{\mathrm{a}} 0.018$

${ }^{\mathrm{b}} 0.002$

${ }^{\mathrm{c}} 0.003$

d 0.036 
Table 3 Questionnaire regarding effects, side effects, and use at follow-up

\begin{tabular}{|c|c|c|c|c|c|}
\hline & \multicolumn{2}{|c|}{$\mathrm{OA}_{\text {Flex }}(n=22)$} & \multicolumn{2}{|c|}{$\mathrm{OA}_{\text {Rigid }}(n=19)$} & \multirow{2}{*}{$\begin{array}{l}\text { Difference } \\
p \text { value }\end{array}$} \\
\hline & Median & IQR & Median & IQR & \\
\hline Adherence ( $\%$ of the nights) & 95 & $80-100$ & 90 & $60-100$ & 0.168 \\
\hline Nightly use (hours) & 7 & $7-7$ & 7 & $5-7$ & 0.170 \\
\hline \multicolumn{6}{|l|}{ Satisfaction with effect on } \\
\hline Snoring & 2 & $2-3$ & 3 & $2-3$ & 0.139 \\
\hline Daytime sleepiness & 2 & $2-3$ & 3 & $2-3$ & 0.145 \\
\hline Overall & 3 & $2-3$ & 3 & $2-3$ & 0.789 \\
\hline Elastic use & 2 & $2-2$ & 1 & $0-2$ & 0.027 \\
\hline Side effects & 1 & $0-1$ & 1 & $0-1$ & 0.649 \\
\hline
\end{tabular}

Satisfaction with the treatment: $0=$ "not satisfied," $1=$ "partially satisfied," 2 = "sufficiently satisfied" to $3=$ "totally satisfied." Elastic use: $0=$ "never," 1 = "sometimes" to $2=$ "always." Side effects: $0=$ "often," 1 = "fairly often," 2 = "seldom" to 3 = "never" after 5 to 11 years' treatment $[1,3,17]$. Rose et al. found no change after 2 years' treatment. More research is needed to explain differences in space changes for the anterior teeth between appliance designs.

To prevent $\mathrm{OA}_{\text {Flex }}$ from causing irregularity, full occlusal coverage with contact on all front teeth, as well as the stabilization of the appliance in the lateral dimension, is therefore recommended, based on the present results. These suggested changes are either already available or can easily be achieved in the computerized production process of this appliance in order for it to be more similar to other more rigid designs.

The overjet was unchanged with both appliances in the present study. The overbite changed with median values of $-0.7 \mathrm{~mm}$ with $\mathrm{OA}_{\text {Flex }}$ and $-0.4 \mathrm{~mm}$ for $\mathrm{OA}_{\text {Rigid, }}$, and there was no difference between the groups. Previous studies have shown mean changes in overjet of between -0.2 and $-1.5 \mathrm{~mm}$ and in overbite of between -0.1 and $-1.8 \mathrm{~mm}$ after 2 years' treatment $[2,4,6,18,20,28]$. Consequently, the present results are in line with previous findings.

We had expected an elongation of the incisors resulting in an increased overbite from the $\mathrm{OA}_{\mathrm{Flex}}$, since this appliance lacks vertical support for the front teeth. It is possible that the contact between the upper and the lower incisors without the appliance during the daytime prevented the incisors from elongation, since the patients had a normal overjet and overbite at the start of treatment. Another explanation might be that the tongue can exert pressure on the incisors during the night, since the appliance lacks material on the lingual side at the front.

Factors such as appliance design, type of bite, and treatment time have been found to influence the degree of change in overjet and overbite during OA treatment. One study revealed no change in overjet and overbite after 4 years' treatment [18]. That study used a specific OA design, with a lack of buccal coverage on the upper incisors and reinforced lower incisor coverage. Another observational study found fewer changes in overjet and overbite with a soft elastomeric device that covered all the teeth, as well as some parts of the alveolar processes, compared with a hard acrylic one with full occlusal coverage that was mainly fixed to the teeth [11]. A specific orthodontic oral appliance with incorporated forces to counteract the posteriorly directed forces on the upper front teeth showed positive effects on overjet changes compared with a control device in a small group of patients [29]. Consequently, a comparison of side effects between appliance designs has essentially not been made. This lack of knowledge is probably explained by the long treatment time that is needed in order to be able to compare tooth movements between various device designs. More research in this field is therefore needed.

There was no difference in patient satisfaction between the two appliance designs. Most likely, changes in the design of the flexible device to make it more rigid will therefore not influence the subjects' treatment satisfaction.

Elastic bands were more frequently used with $\mathrm{OA}_{\mathrm{Flex}}$ than with $\mathrm{OA}_{\text {Rigid }}$ in our study. One possible explanation may be that elastics usually have to be applied every day to the $\mathrm{OA}_{\text {Rigid, }}$, while they can stay in place until they are worn out on the $\mathrm{OA}_{\text {Flex }}$. In addition, one study has shown that patients prefer to use elastics on $\mathrm{OA}_{\text {Flex }}$ [30], while this is unknown for $\mathrm{OA}_{\text {Rigid }}$. Although unknown, the use of elastics in a flexible device might produce additional unforeseen changes in the dentition.

There are limitations to the present study. First, the study was retrospective, which may have introduced some bias in terms of patient selection. Patients who had experienced bite changes with the appliance might have stopped using it. On the other hand, the results of the study confirmed the complaint from our patient. Complaints of this kind are fairly rare, since most patients are unaware of bite changes. Between 4 and $14 \%[12,15]$ of patients have been reported to notice occlusal changes, although $86 \%$ of patients have been found to have these objective changes [1]. After completion of this 
study, a few more patients have spontaneously reported the same complaint as the patient who was the reason we started this study.

In conclusion, the present results indicate that a flexible type of OA without incisor coverage increases the irregularity of the lower front teeth compared with a more rigid OA with incisor coverage.

\section{Compliance with ethical standards}

Funding The County Council of Västerbotten provided financial support in the form of grant funding. The sponsor played no role in the design or conduct of this research.

Conflict of interest The authors certify that they have no affiliations with or involvement in any organization or entity with any financial interest (such as honoraria; educational grants; participation in the speakers' bureaus; membership, employment, stock ownership, or other equity interest; and expert testimony or patent-licensing arrangements) or non-financial interest (such as personal or professional relationships, affiliations, knowledge, or beliefs) in the subject matter or materials discussed in this manuscript. Marie Marklund has received a consultant fee from ResMed.

Ethical approval All procedures performed in studies involving human participants were in accordance with the ethical standards of the institutional and/or national research committee and with the 1964 Helsinki Declaration and its later amendments or comparable ethical standards.

Informed consent Informed consent was obtained from all individual participants included in the study.

Open Access This article is distributed under the terms of the Creative Commons Attribution 4.0 International License (http:// creativecommons.org/licenses/by/4.0/), which permits unrestricted use, distribution, and reproduction in any medium, provided you give appropriate credit to the original author(s) and the source, provide a link to the Creative Commons license, and indicate if changes were made.

\section{References}

1. Almeida FR, Lowe AA, Otsuka R, Fastlicht S, Farbood M, Tsuiki S (2006) Long-term sequellae of oral appliance therapy in obstructive sleep apnea patients: part 2. Study-model analysis. Am J Orthod Dentofac Orthop 129:205-213

2. Bondemark L (1999) Does 2 years' nocturnal treatment with a mandibular advancement splint in adult patients with snoring and OSAS cause a change in the posture of the mandible? Am J Orthod Dentofac Orthop 116:621-628

3. Chen H, Lowe AA, de Almeida FR, Fleetham JA, Wang B (2008) Three-dimensional computer-assisted study model analysis of longterm oral-appliance wear. Part 2. Side effects of oral appliances in obstructive sleep apnea patients. Am J Orthod Dentofac Orthop 134:408-417

4. Doff MH, Finnema KJ, Hoekema A, Wijkstra PJ, de Bont LG, Stegenga B (2013) Long-term oral appliance therapy in obstructive sleep apnea syndrome: a controlled study on dental side effects. Clin Oral Investig 17:475-482
5. Fransson AM, Tegelberg A, Johansson A, Wenneberg B (2004) Influence on the masticatory system in treatment of obstructive sleep apnea and snoring with a mandibular protruding device: a 2year follow-up. Am J Orthod Dentofac Orthop 126:687-693

6. Fritsch KM, Iseli A, Russi EW, Bloch KE (2001) Side effects of mandibular advancement devices for sleep apnea treatment. Am J Respir Crit Care Med 164:813-818

7. Ghazal A, Jonas IE, Rose EC (2008) Dental side effects of mandibular advancement appliances - a 2-year follow-up. J Orofac Orthop 69:437-447

8. Gong X, Zhang J, Zhao Y, Gao X (2013) Long-term therapeutic efficacy of oral appliances in treatment of obstructive sleep apneahypopnea syndrome. Angle Orthod 83:653-658

9. Hammond RJ, Gotsopoulos H, Shen G, Petocz P, Cistulli PA, Darendeliler MA (2007) A follow-up study of dental and skeletal changes associated with mandibular advancement splint use in obstructive sleep apnea. Am J Orthod Dentofac Orthop 132:806-814

10. Hou HM, Sam K, Hagg U, Rabie ABM, Bendeus M, Yam LYC, Ip MS (2006) Long-term dentofacial changes in Chinese obstructive sleep apnea patients after treatment with a mandibular advancement device. Angle Orthod 76:432-440

11. Marklund M (2006) Predictors of long-term orthodontic side effects from mandibular advancement devices in patients with snoring and obstructive sleep apnea. Am J Orthod Dentofac Orthop 129:214221

12. Marklund M, Franklin KA, Persson M (2001) Orthodontic sideeffects of mandibular advancement devices during treatment of snoring and sleep apnoea. Eur J Orthod 23:135-144

13. Martinez-Gomis J, Willaert E, Nogues L, Pascual M, Somoza M, Monasterio C (2010) Five years of sleep apnea treatment with a mandibular advancement device. Side effects and technical complications. Angle Orthod 80:30-36

14. Nakamura S, Sato M, Mataki S, Kurosaki N, Hasegawa M (2009) Subjective and objective assessments of short-term adverse effects induced by oral appliance therapy in obstructive sleep apnea: a preliminary study. J Med Dent Sci 56:37-48

15. Pantin CC, Hillman DR, Tennant M (1999) Dental side effects of an oral device to treat snoring and obstructive sleep apnea. Sleep 22: 237-240

16. Perez CV, de Leeuw R, Okeson JP, Carlson CR, Li HF, Bush HM, Falace DA (2013) The incidence and prevalence of temporomandibular disorders and posterior open bite in patients receiving mandibular advancement device therapy for obstructive sleep apnea. Sleep Breath 17:323-332

17. Pliska BT, Nam H, Chen H, Lowe AA, Almeida FR (2014) Obstructive sleep apnea and mandibular advancement splints: occlusal effects and progression of changes associated with a decade of treatment. J Clin Sleep Med 10:1285-1291

18. Ringqvist M, Walker-Engstrom ML, Tegelberg A, Ringqvist I (2003) Dental and skeletal changes after 4 years of obstructive sleep apnea treatment with a mandibular advancement device: a prospective, randomized study. Am J Orthod Dentofac Orthop 124:53-60

19. Robertson C, Herbison P, Harkness M (2003) Dental and occlusal changes during mandibular advancement splint therapy in sleep disordered patients. Eur J Orthod 25:371-376

20. Rose EC, Staats R, Virchow C Jr, Jonas IE (2002) Occlusal and skeletal effects of an oral appliance in the treatment of obstructive sleep apnea. Chest 122:871-877

21. Ueda H, Almeida FR, Lowe AA, Ruse ND (2008) Changes in occlusal contact area during oral appliance therapy assessed on study models. Angle Orthod 78:866-872

22. Wang X, Gong X, Yu Z, Gao X, Zhao Y (2015) Follow-up study of dental and skeletal changes in patients with obstructive sleep apnea and hypopnea syndrome with long-term treatment with the Silensor appliance. Am J Orthod Dentofac Orthop 147:559-565 
23. Cohen-Levy J, Petelle B, Pinguet J, Limerat E, Fleury B (2013) Forces created by mandibular advancement devices in OSAS patients: a pilot study during sleep. Sleep Breath 17:781-789

24. Sutherland K, Vanderveken OM, Tsuda H, Marklund M, Gagnadoux F, Kushida CA, Cistulli PA (2014) Oral appliance treatment for obstructive sleep apnea: an update. J Clin Sleep Med 10: 215-227

25. Marklund M, Verbraecken J, Randerath W (2012) Non-CPAP therapies in obstructive sleep apnoea: mandibular advancement device therapy. Eur Respir J 39:1241-1247

26. Sharples LD, Clutterbuck-James AL, Glover MJ, Bennett MS, Chadwick R, Pittman MA, Quinnell TG (2016) Meta-analysis of randomised controlled trials of oral mandibular advancement devices and continuous positive airway pressure for obstructive sleep apnoea-hypopnoea. Sleep Med Rev 27:108-124

27 Little RM (1975) The irregularity index: a quantitative score of mandibular anterior alignment. Am J Orthod 68:554-563

28 Fransson AM, Tegelberg A, Svenson BA, Lennartsson B, Isacsson $G$ (2002) Influence of mandibular protruding device on airway pas- sages and dentofacial characteristics in obstructive sleep apnea and snoring. Am J Orthod Dentofac Orthop 122:371-379

29 Marklund M, Legrell PE (2010) An orthodontic oral appliance. Angle Orthod 80:1116-1121

30 Norrhem N, Marklund M (2016) An oral appliance with or without elastic bands to control mouth opening during sleep-a randomized pilot study. Sleep Breath 20:929-938

\section{Comment}

The article is an important suggestion for OA therapy to consider appliance designs and material, there are many types of commercial devices on the market without these evaluations. This report is giving a useful opinion to avoid some dental side effect.

Morio Tonogi

Tokyo, Japan 